\title{
Teacher Competence in Continuous and Comprehensive Evaluation System
}

\author{
Thanuja.K \\ Associate Professor, Keyi Sahib Training College, Karimbam, Taliparamba, Kannur, Kerala
}

\begin{abstract}
The main purpose of CCE is quality education. That means continuous and comprehensive evaluation aims at the development of the child's intellectual, physical and mental abilities through various experiences gained in and outside the classroom. For that it is important to equip teachers with required skills and competencies of evaluation well with the teaching-learning process. The teacher plays a major role in imparting competency based teaching and skill in evaluation for realising the holistic development of the child.

Keywords: Evaluation, Assessment, Continuous and comprehensive evaluation, teacher competence
\end{abstract}

\section{Introduction}

The right of children to Free and Compulsory Education Act, 2009 (RTE Act 2009) implemented since April 2010 chapter V of the Act on Curriculum and completion of Elementary Education under section 29 (1) (h) provides for comprehensive and continuous evaluation of child's understanding of knowledge and his or her ability to apply the same. In view of this various efforts have been made by states and union territories to develop CCE materials and evolve strategies for its implementation. Research on evaluation practices revealed that teachers are facing problems in the understanding and implementation of CCE. Continuous internal assessment is not followed systematically in most of the schools. Competencies are not assessed through planned procedure of evaluation. The reporting procedures have also been found to be a mechanical and cumbersome exercise for teachers. Apart from this, there are misconceptions related to various terms such as continuous, comprehensive evaluation, assessment, formative and summative assessment, which created confusion in the system. Practitioners are interpreting CCE in their own way.

\section{Evaluation And Assessment}

Evaluation is an integral part of any teaching and learning programme. The quality of education is directly linked with the quality of evaluation. Both teaching and evaluation are based on the instructional objectives which give the teachers direction. Instructional objectives are those desirable behaviours which are to be developed in students through the learning process. These are reflected in the form of syllabus, instructional material and information given by the teachers, and evaluation is done to see whether the instructional objectives have been achieved and to what extent. The three components of teaching, learning and evaluation constitute an integrated network. Through evaluation the teacher not only assesses as to how far the students have achieved the objectives, but also examines the effectiveness of the teaching strategy, teaching materials as well as teaching methodology. Evaluation is a process by which we can collect evidences for student's progress. By analyzing the collected data we can record observations about an individual and then teacher can adopt corrective measure, for better learning of the child. In short, it involves systematic collection, analysis and interpretation of the learner's progress both in scholastic and co-scholastic areas of learning to provide constant feed back about the effectiveness of course content, classroom processes and the growth in individual learners.

Assessment is defined as the process of obtaining information that is used to make educational decisions about students, to give feedback to the students about his or her progress, strengths and weaknesses, to judge instructional effectiveness and curricular adequacy, and to inform policy. The various assessment techniques include but are not limited to, formal, informal observation, qualitative analysis of pupil performance and products, paper-pencil tests, oral questioning and analysis of student records. Thus assessment is the process of gathering information from a variety of sources that accurately reflect how well a student is achieving the curricular expectations in a subject. Assessment therefore needs to be used as a means of gathering evidences to meet the requirements of evaluation.

\section{Continuous And Comprehensive Evaluation}

The main objective of continuous and comprehensive evaluation is the all round development of the child. That means CCE helps to develop cognitive, affective and psychomotor skills of the pupil CCE scheme refers to a school - based evaluation of students that covers all the aspects of a student's development.

In the scheme of continuous and comprehensive evaluation the term "continuous" is meant to emphasis that evaluation of identified aspects of student's growth and development is a continuous process rather than an 
event, built into the total teaching learning process and spread over the entire span of the academic session. It means regularity of assessment, frequency of unit testing, diagnosis of learning gaps, use of corrective measures retesting and feedback of evidence to teachers and student for their self - evaluation.

The term "comprehensive" means that the scheme attempts to cover both the scholastic and non scholastic aspects of students" growth and development. Since abilities, attitudes and aptitudes can manifest themselves in forms other than written words, the term refers to the application of a variety of tools and techniques (both testing and non testing ) and aims at assessing a learner's development in the various areas of learning (CBSE manual 2009, P-5)

\section{Teacher Competencies For Student Assessment}

Teacher's competencies for student assessment in class rooms are described in terms of the following assessment paradigms

\section{Assessment Competencies prior to instruction:}

The main purpose of class room instruction is to help students achieve a set of intended learning goals. These goals should typically include desired changes in the intellectual, emotional and physical spheres. When class room instruction is viewed in this light, assessment becomes an integral part of the teaching learning process. At this phase, the teacher must be competent in placement assessment, that is to determine student performance at the beginning of instruction. This assessment is concerned with the student's entry performance and typically focuses on the questions such as the following (a) Does the child possess the knowledge and skills needed to be begin the planned instruction? To what extent has the child already developed the understanding and skills that are the goals of the planned instruction? To what extent do the students interests, work habits and personality characteristics indicate that the one mode of instruction might be better than the other. ?

To answer these questions require a variety of tasks and techniques like pretest on course objectives, record of past achievement, testing entry behaviour, and observational technique can be utilized. Based on the assessment gathered the teacher decides the goals of instruction. Well stated outcomes make clear the types of student performance that the teacher is willing to accept as evidence that instruction has been successful.

\section{- Assessment Competencies during Instruction:}

Relevant instruction takes place when course content and teaching methods are integrated into planned instructional activities designed to help students to achieve the intended learning outcome. During this instructional phase, assessment provides a means of monitoring learning progress and diagnosing learning difficulties. Thus, periodic assessment during instruction provides a type of feed back, enabling the designing of corrective procedures that aid in continuously adapting instruction to group and individual needs. That means assessment for learning and assessment as learning takes place during instruction. Assessment for learning involves increased levels of student autonomy. There is more emphasis towards giving of useful advice to the student and less emphasis on the giving of marks and the grading function. The teacher designs learning experiences and assessment with feed back to the students and assesses what has been learnt. Assessment as learning is more connected with diagnostic assessment and can be constructed with more of an emphasis on informing learning. Assessment as learning generates opportunities for self assessment and peer assessment. Students took an increased responsibility to generate quality information about their learning and that of others. The main feature of this type of assessment is that the teacher and learner co-construct learning and assessment. Assessment for learning and assessment as learning activities should be deeply embedded in teaching and learning and be the source of interactive feed back allowing students to adjust, rethink and re-learn. So the assessment competency required for teacher during instruction is to monitor the learning progress of the child based on the objectives, immediate feed back, diagnosis and remediation.

\section{- Assessment competencies after appropriate instructional treatment}

After providing appropriate instructional strategies, teacher collects evidence to judge what extent learning has been achieved. This is known as assessment of learning. Assessment of learning refers to strategies designed to confirm what students know to demonstrate, whether or not they have met curriculum outcomes or the goals of their individualized programs, or to certify proficiency and make decisions about student's future programme or placements. It is designed to provide evidence of achievement to parents, other educators the students themselves and someone outside the group.

Teachers have the responsibility of enabling the student to learn accurately and fairly, based on evidence obtained from a variety of contexts and applications. Effective assessment of learning requires that the teacher must be competent in the following aspects:

- rationale for understanding a particular assessment of learning at a particular point of time.

- clear descriptions of the intended learning 
- processes that make it possible for students to demonstrate their competence and skill

- a range of alternative mechanisms for assessing the same outcome.

$\circ$ transparent approaches to recording and interpretation of results

- description of the assessment process before and during instruction to understand each student progress and to inform future instructional planning.

- evaluating the effectiveness of instruction and curriculum

○ communicating strengths and weaknesses based on the assessments results to students, parents and guardians.

\section{Teacher Competence In Assessment of Students In The Continuous And Comprehensive Evaluation System}

1. Teacher must have a thorough knowledge of the concept and objectives of continuous and comprehensive evaluation.

- Continuous and Comprehensive Evaluation (CCE) refers to a system of School based evaluation of students that covers all aspects of student's development

- The 'Continuous' aspect of CCE takes care of 'continual' and periodicity of evaluation.

- Continual means assessment of students in the beginning of instructions. (placement evaluation) and assessment during the instructional process (formative evaluation ) done informally using multiple techniques of evaluation.

- Periodicity means assessment of performance done frequently at the end of unit / term (summative) using criterion - referenced tests and employing multiple techniques of evaluation.

- The 'comprehensive' component of CCE takes care of assessment of all round development of the child's personality. It includes assessment in scholastic as well as co-scholastic aspects of the pupils growth.

- Scholastic aspect include curricular areas or subject specific areas, whereas co-scholastic aspects include Life skills, attitudes, values and co-curricular activities.

- Assessment in scholastic areas is done informally and formally using multiple techniques of evaluation continually and periodically. The diagnostic evaluation takes place at the end of unit or term test. The causes of poor performance in some units are diagnosed using diagnostic tests. These are purposefully remediated by giving interventions followed by retesting.

- Assessment in co-scholastic is done using multiple techniques on the basis of identified criteria, while assessment in life skills, attitudes, values and co-curricular activities is done by using behaviour indicators.

2. Teachers should be skilled in choosing assessment tasks, method, strategies, tools and techniques appropriate for continuous internal assessment and comprehensive assessment.

- Skills in choosing appropriate, useful, administrative. convenient, technically adequate and fair assessment methods are pre requisite to good use of information to support instructional decisions. The teachers will know, each assessment approach they use and its appropriateness for making decisions about their pupils. Assessment options are diverse and include text and curriculum embedded questions, port folios, discussions, quiz programme, role playing, exhibitions, demonstrations, oral test, written test, performance test, practical work, peer and self assessment, group activity, observations, interviews, others opinion, student records, speech, drama criterion referenced test, norm referenced test, diagnostic test and performance task. One of the feature of CCE is performance assessment. Performance assessment provide a basis for teachers to evaluate both the effectiveness of the process or procedure used and the product resulting from performance of a task.

- For assessing performance task, the important points to be noted are the following:

The teacher must :

$>$ Focus on learning outcomes that require complex student performance select or develop tasks that represent both the content and the skills that are central to important learning outcomes.

$>$ Minimize the dependence of task performance on skills that are irrelevant to the intended purpose of the assessment task.

$>$ Provide the necessary scaffolding for students to be able to understand the task and what is expected.

$>$ Construct task directions so that the student's task is clearly indicated. Use indicators for clearly observable and measurable behavioiurs.

$>$ Clearly communicate performance expectations in terms of the scoring rubrics by which the performance will be judged. So the teacher should consider the above mentioned points while choosing performance tasks in and outside the class room .

3. Teachers should be skilled in developing assessment methods appropriate for instructional decisions.

CCE demands teachers to adopt a variety of tools and techniques. Most of the assessment methods and tools are not readily available. Teachers will be skilled in planning the collection of information that facilitates 
the decisions they will make. They will know and follow appropriate principles for developing and using assessment methods in their teaching, avoiding common pit falls in student assessment. The teacher will be efficient in selecting, developing and the techniques which are appropriate to the intent of the teacher's instruction.

4. The teacher should be skilled in administering both externally produced and teacher produced assessment methods

Teacher should be skilled in administering diverse assessment methods. Teacher must be well aware of how to conduct an individual work, group work, peer reporting and self reporting technique etc. For that teacher must be clear about the purpose or objective of each assessment task and the criteria of recording and interpretation.

5. Teachers should be skilled in recording assessment methods and techniques appropriate for instructional decisions.

Classroom interactions (inside and outside) provides a wide range of opportunities to make observations of a child's behaviour and learning. Some of the observations are made on daily basis in an informal manner while teaching - learning is going on. Day to day observations are forgotten if not recorded. Still others are planned observations of children on activities given to them. This type of observation is planned with a purpose and is thus more formal in nature. To provide a more complete picture of the child's learning and progress, the scope needs to be widened. Recording needs to include records of observations and comments on children's performance on assignments, ratings of what children do and how they behave and anecdotes or incidents of children's behavior towards others.

For example, the teacher can keep a portfolio as a record of a child's work. It is purposeful collection of pieces of student work. Portfolio's are sometimes described as portraits of a persons' accomplishments. Portfolios should not contain only the best work but all kinds of work, to show the progress of a child over an entire period in respective class. Such a collection shows the teachers and parents what the child has accomplished and various abilities of the child. At the end of every term, the teacher can study each child's portfolio and give specific and useful feed back to parents. It helps parents to know more about their child's abilities and interests which they may not have observed at home.

6. The teacher should be skilled in making sense of the information recorded. That means scoring and interpreting the results of both externally produced and teacher produced assessment methods.

Once information has been recorded, the next important step is using available evidence to arrive at an understanding of what has been collected and recorded. What this results in drawing conclusions about how a child is learning and progressing. This is necessary in order to understand 'where the child is and what needs to be done to help the child' . In the case of qualitative evaluation, proper interpretation would require identification of indicators to facilitate the process. For interpreting life skills, attitude, values, club activities, and other activities, and other aspects in co-scholastic area teacher can follow indicators developed jointly by NCERT and MHRD and also rubrics. A scoring rubric in a set of guidelines for the application of performance criteria to the responses and performance of students. A scoring rubric typically consist of verbal descriptions of performance or aspects of student responses that distinguish between advanced, proficient, partially proficient and the beginning levels of performance. There are two types of rubrics : analytic scoring rubric and holistic scoring rubric. The analytic scoring rubric requires the identifications of different dimensions or characteristic of performance that are rated separately. A holistic rubric provides descriptions of different levels of overall performance. Holistic rubrics are efficient and correspond more directly to global judgments required in the assignment of grades, but they do not provide the students with specific feed back about the strengths and weaknesses of their performance as is provided by the analytic rubrics.

Teacher will be skilled in interpreting informal and formal teacher produced assessment results, including pupils performance in class and on home work, assignments etc. The teacher will be able to score standardized tests and abe able to interpret raw scores into standard scores. For that knowledge in elementary statistics is a must.

The teacher must be skilled in developing valid pupil grading procedures. In CCE subjects related scholastic areas are interpreted in terms of indirect grading. That means converting marks into grades, usually criterion referenced grading. In the case of non-scholastic area, direct and norm referenced grading are followed

Teachers must have the conceptual and application skills in the grading system that he/ she follows. $\mathrm{He} / \mathrm{she}$ must be able to devise, implement, and explain a procedure for developing grades composed of mark from various assignments, projects, class activities, quizzes, tests and other assessments that they may use. The 
teacher must understand and be able to articulate why the grades they assign are rational, justified, and fair, acknowledging that such grades reflect their preferences and judgment's.

7. The teachers should be skilled in reporting and communicating feed back on assessment. The teacher must routinely report assessment results to students and to parents or guardians. Usually this is done through a report card. Report card should provide a profile of the child's progress over a specified period of time. If the results are not communicated effectively they may be misused or not used. To communicate effectively with others on matters of student assessment, the teacher must be able to use assessment terminology appropriately and must be able to articulate the meaning, limitations and implications of assessment results.

On preparing a report the teacher needs to communicate and share the feed back with the child and parents. This aspect is important and needs to be done carefully and in a constructive and positive manner.

\section{Conclusion}

The main objective of continuous and comprehensive evaluation is quality education. For developing quality education, teachers must be efficient in teaching as well as in assessment practices in and outside the class room. CCE has been fruitful in improving the evaluation skills of the teachers which is very important. The competence expected of them is be able to raise the standard of achievement in pupils by constant feedback, remediation and improvement of classroom instructional strategies based on the evaluation results. Moreover comprehensive assessment of every aspect of changes in physical, emotional and intellectual spheres must be evaluated. This in turn results in the improvement of quality education. It is important to equip teachers with required skills and competencies of evaluation so that they will be able to integrate evaluation well with the teaching - learning process.

\section{References}

[1]. Aggarwal. J.C. (2005) Essentials of Examination system. New Delhi : Vikash Publishing House Pvt Ltd.,

[2]. Aseefa Mesert (2008), "Analysis of Evaluation System in different Departments at the College of Education". Journal of Indian Education Vol.34, No. 3, PP-106-126

[3]. CBSE (2009) Teacher's Manual on CCE, New Delhi: CBSE,

[4]. Cronbach, L.J (1984), Essential of Psychological Testing, New York; Harper \& Row.

[5]. SCERT (2007) Kerala Curriculum Frame work. Thiruvananthapuram State Council of Educational Research and Training 